\title{
NON-TRAUMATIC ADHESIVE ARACHNOIDITIS AS A CAUSE OF SPINAL CORD SYNDROMES. INVESTIGATION ON 507 PATIENTS $\dagger$
}

\author{
By F. Jenik, M.D., ${ }^{1 \star}$ Redda Tekle-Haimanot, M.D. ${ }^{1}$ and \\ B. H. HAMORY, L.C.D.R. ${ }^{2}$ \\ 1 Swiss Paraplegic Centre, Im Burgfelderhof 40, Ch4055, Basel, Switzerland \\ ${ }^{2}$ U.S. Naval Medical Research Unit, No. 5, Addis Ababa, Ethiopia
}

\begin{abstract}
Epidemiology and pathogenesis of spinal cord syndromes due to adhesive arachnoiditis are discussed. The similarity of those syndromes with classical syringomyelias is pointed out. Two studies in Ethiopia indicate that in the majority of patients there is no benefit from treatment with antibiotics and steroids.
\end{abstract}

Key words: Non-traumatic adhesive arachnoiditis; Spinal cord syndromes; Syringomyelic sensory pattern; Radiculo-myelopathy.

\section{Introduction}

ADHESIVE spinal arachnoiditis, a rather rare condition in Europe, is a common problem in the developing world. Several earlier authorities from the numerous papers on the issue should be mentioned here (Charcot \& Joffroy, I869; Joffroy, 1873; Horsley, 1909; Elkington, 1936). Arachnoiditis after tuberculous meningitis was described by Brouwer (I93I), Ransome and Montiero (1947), Arseni and Samitca (1960), Bawa and Wahi (I96I), Jenkins (1963), Parsons and Pallis (1965), Wadia and Dastur (1969), Dastur and Wadia (1969), Tandon and Pathak (1973), Wadia (1973), Freilich and Swash (1979) and others.

In the course of 2 years in the newly established Neurological Unit of the Department of Medicine at the Black Lion Hospital, University of Addis Ababa, we saw 1305 new patients, including 507 patients with symptoms suggestive of arachnoiditis. We undertook a retrospective study of I54 patients seen between January and December 1976 and a prospective study of 353 seen between January and October 31, 1977, at which time the investigation had to be terminated.

Methods of assessment. In addition to a detailed neurological examination all patients of the prospective study had a full blood count, ESR and blood urea nitrogen determination. The VDRL test of serum was performed in all prospective study patients and the Mantoux test in II4 consecutive cases. The

\footnotetext{
* Present address and address for reprints: Swiss Paraplegic Centre, Im Burgfelderhof 40, $\mathrm{CH}-4055$ Basel/Switzerland.

† Based on a preliminary report at the Fourth Annual Conference of Neurological Society of Kenya, Nairobi, I9 March 1977 as well as a further completed paper read at XIIIth Annual Medical Conference of the Ethiopian Medical Association, Addis Ababa, 26 May 1977.
} 
CSF was examined in 60 per cent of prospective study patients and a myelogram was performed in 105. Radiographs of the spine were taken in the majority of patients.

\section{Results}

The patients came from all parts of Ethiopia. There were five 'foreigners'three Europeans and two Asians. All the non-Ethiopians had lived in the country for at least I-2 years before the onset of symptoms. Patients from all socioeconomic groups were seen, although the majority came from the lowest.

Age and sex. Table I shows that the age ranged from 7-65 years (mean 3I) and that men were more frequently affected than women (ratio $3: 2$ ).

\section{TABLE I}

Age and sex distribution

\begin{tabular}{|c|c|c|c|c|}
\hline Age & Males & Females & Total & $\%$ \\
\hline 7-10 years & I & - & I & 0.2 \\
\hline I I-I 5 years & 8 & 4 & I 2 & $2 \cdot 3$ \\
\hline I6-20 years & 28 & 32 & 60 & II $\cdot 8$ \\
\hline $2 \mathrm{I}-25$ years & 63 & 40 & 103 & $20 \cdot 3$ \\
\hline $26-30$ years & 62 & 53 & II 5 & $22 \cdot 7$ \\
\hline $3 \mathrm{I}-35$ years & 47 & 17 & 64 & $12 \cdot 6$ \\
\hline $36-40$ years & 42 & I7 & 59 & II 6 \\
\hline $4 \mathrm{I}-45$ years & 32 & 9 & $4 \mathrm{I}$ & $8 \cdot I$ \\
\hline $46-50$ years & 15 & I2 & 27 & $5 \cdot 3$ \\
\hline $5 \mathrm{I}-55$ years & 6 & 4 & IO & $2 \cdot 0$ \\
\hline $56-60$ years & 9 & 2 & I I & $2 \cdot I$ \\
\hline $6 I-65$ years & 2 & 2 & 4 & 0.8 \\
\hline Total & $315 / 62 \cdot 1 \%$ & $192 / 37.9 \%$ & 507 & 100 \\
\hline Mean age & $3 I \cdot 9$ years & 29.5 years & $3 I \cdot 0$ years & \\
\hline
\end{tabular}

Onset. Of 255 consecutive prospective study patients the onset was insidious in I60, i.e. 62.7 per cent. In $65(25.5$ per cent) the neurological symptoms began acutely or subacutely following a febrile illness characterised by malaise, nausea and sometimes stiff neck. In 30 patients (I I 8 per cent) the neurological symptoms began subacutely without awareness of a preceding acute illness, (with the exception of patients with a history of gonorrhoea or syphilis occurring a year or more before).

Patients in the prospective series (255) presented the following complaints of dull pain in the lumbar region with sensory and motor symptoms in the legs, with or without sensory and motor symptoms and pain in the neck, shoulders and arms. Other patients complained of a burning sensation in the head and frequently of headache. Sphincter disturbances (20 per cent) and decreased sexual potency (3I per cent) were relatively common. Finally, symptoms of intracranial disorders were sometimes encountered-dizziness and loss of balance ( 13 per cent), impairment of hearing (18.5 per cent), epilepsy ( 5 per cent) and some with memory impairment. 
Course-duration of symptoms

Progression of the symptoms was usually gradual with even long periods of relative stabilisation. At one extreme there were patients who had had symptoms for 10 to 20 years with relatively little disability. At the other end there were occasional patients with an abrupt onset of symptoms which progressed to severe paraparesis or even paraplegia within a few weeks or months.

\section{Physical examination (Table II)}

Full details of the physical signs were available in 200 patients in the prospective group. They are shown in Table II. The outstanding feature was a dissociated sensory decrease or a loss of syringo-myelic type, present in 180 (90 per cent). There was maximum impairment of pain and diminution of temperature sensation in the area $\mathrm{C}_{4} / 5$ down to $\mathrm{T}_{5} / 6(7 / 8)$ distribution and $\mathrm{LI}_{\mathrm{I}} \mathrm{L}_{4}$ (5) (occasionally down to S2/3) segments. This sensory decrease or loss was usually bilateral, more or less symmetrical (unilateral in 9.5 per cent). This was combined with a similarly dissociated sensory loss of 'onion peel' type in the trigeminal distribution of the face ( 88 per cent) with variable sparing of the nose and its vicinity. Only a few patients were (except I-2 'peels' at the nose) almost completely 'dull', that is insensitive to strong pinching and pricking down to $\mathrm{S}_{5}$.

All patients showed either a tendency for or positive pyramidal signs in the upper and lower extremities, more often in the latter. The upper limb tendon jerks were diminished in 47 patients (23.5 per cent), atrophies of arm and hand muscles occurred in 27 (13.5 per cent), and of leg muscles in 23 (I I.5 per cent). In 12 patients the signs were restricted to a single localised spinal cord region, mimicking tumour or transverse myelitis with deficiencies of all sensory modalities and severe paraparesis or paraplegia.

\section{TABLE II}

Physical signs in 200 consecutive prospective study patients

\begin{tabular}{|c|c|c|}
\hline Symptoms & Number & $\%$ \\
\hline \multirow{3}{*}{$\begin{array}{l}\text { Dissociated sensory decrease-loss of syringomyelic type } \\
\text {-included nuclear trigeminal involvement of 'onion peel' type } \\
\text { Spastic signs, more marked in the lower limbs }\end{array}$} & I80 & 90 \\
\hline & I 76 & 88 \\
\hline & 200 & 100 \\
\hline Exaggerated jaw jerk & 152 & 76 \\
\hline Sucking reflex & 35 & 17.5 \\
\hline Tendon jerks diminished in the upper limbs & 47 & $23 \cdot 5$ \\
\hline \multirow[t]{2}{*}{ Muscular wasting in the arms and hands } & 27 & 13.5 \\
\hline & 23 & II $\cdot 5$ \\
\hline Argyll Robertson pupils & 48 & 24 \\
\hline Nystagmus on conjugate lateral gaze & 52 & 26 \\
\hline Decrease of hearing & 37 & $18 \cdot 5$ \\
\hline of deafness & 2 & I \\
\hline \multicolumn{3}{|l|}{ Diplopia, internuclear ophthalmoplegia, peripheral facial palsy, } \\
\hline Papilloedema & 5 & $2 \cdot 5$ \\
\hline \multirow{2}{*}{\multicolumn{3}{|c|}{$\begin{array}{l}\text { Slight to moderate diminution of postural sensibility and vibration } \\
\text { sense }\end{array}$}} \\
\hline & 70 & 35 \\
\hline
\end{tabular}




\section{Investigations}

Apart from a tendency towards a relative lymphocytosis in the blood, routine laboratory investigations were within normal limits except in those patients with other concomitant illnesses.

\section{Cerebrospinal fluid (CSF)}

In most patients the cell count was normal. In a small number examined during a sub-acute phase there was a pleocytosis of $20-118 \mathrm{~mm}^{3}$. Glucose levels were normal. The protein concentration was normal except in patients with obstruction in the spinal subarachnoid space in whom levels of $60-80 \mathrm{mg}$ per cent were found.

Bacteriological and virological examination (in 40 and eight cases respectively) revealed no abnormality. Tuberculous bacilli culture and guinea-pig inoculation in I9 consecutive patients were negative. None of the patients admitted for lumbar puncture was in a highly acute phase.

\section{Serology}

In the prospective series (Table III) the VDRL test on serum was positive in I 5 per cent ( 53 of 353 patients), as compared to I I per cent for the population of Addis Ababa (Friedmann, 1976). Yaws does not occur in Addis Ababa and its surrounding provinces. The FTA test was done in many patients with a positive VDRL and always confirmed the VDRL reaction. Positive VDRL or FTA was never found in CSF.

\section{Mantoux Test (I : 5000)}

This test was positive in IO4 (92 per cent) out of II 4 consecutive cases, as compared to a positive rate of 64 per cent in the general population in Addis Ababa and surrounding areas (Teklu, 1975).

\section{Radiological examination of the spine}

This was carried out in most of the cases in the prospective series, amounting to over 60 per cent of the overall number of patients. Apart from plain X-ray changes, found in association with e.g. rudimentary cervical ribs, old compression fractures of the vertebral bodies, fluorosis of the spine or suspected disc prolapse (excluded from the study), no significant abnormalities were found in the remainder.

\section{Myelography}

Myelography with oil was performed in I05 patients with spinal cord syndromes. Evidence of arachnoiditis without other abnormalities was found in 95 out of I05 patients. The most common findings (similar to those of Lombardi et al., 1962; Shaw et al., 1978) were adhesions (the finest of them could be seen rupturing when the table was tilted rapidly), filling defects, narrowing of one or more segments or sometimes complete obstruction of the subarachnoid space, fixity of previously inserted oil contrast medium, obliteration of the nerve root sleeves and pseudocyst formation. In 80 patients the changes were diffuse, usually predominant in the $\mathrm{C}_{7}-\mathrm{T} 8$ segments, but frequently extending up to the high cervical 
region and thereby reducing or preventing the flow of the contrast medium into the cisternal spaces in the supine myelogram. Adhesions in the lumbar region were less common. (Illustrative myelograms, Figures I to 5).

\section{Pneumo-encephalography}

Pneumo-encephalography was performed on 35 patients, particularly in those with headache and cranial nerve deficiencies. In ten patients the air did not enter the ventricles. In three of these patients hydrocephalus was indirectly demonstrated by carotid angiography.

\section{Treatment}

A randomised trial of anti-tuberculous chemotherapy, with or without steroids by mouth and intrathecally, was initiated but had to be abandoned after Io months. There were four groups of patients, each comprised of 15 patients: patients with chemotherapy (group I); patients with chemotherapy and steroids

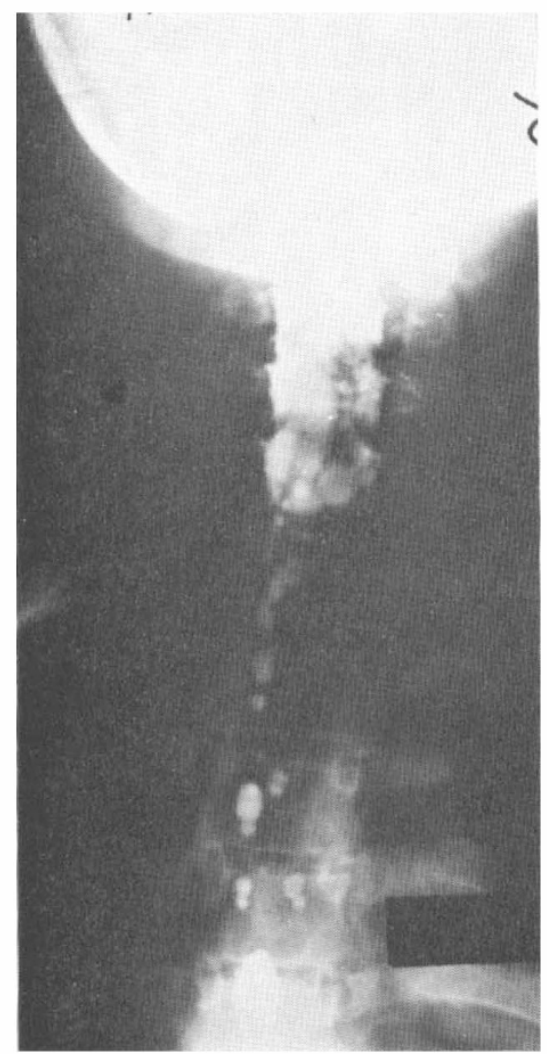

FIG. I

Marked narrowing and irregularity of the contrast medium flow T8 up to C6 on the right side with maximum on $\mathrm{T}_{3}-\mathrm{C} 6$, cervical section slightly widened. In the upright position of the patient the oily medium was observed dropping down only by slight coughing manoeuvres. Fixity signs were also observed in the region. 
by mouth (group 2); patients with chemotherapy and steroids by mouth and intrathecally (group 3); untreated control group (four). No obvious differences between the four groups have emerged. However, the follow-up period has been too short to draw any definite conclusions.

The 53 VDRL positive patients were initially treated with Penicillin and/or Tetracycline. Later, steroids by mouth and/or intrathecally were given. No benefit was observed, but again the follow-up period was too short.

Laminectomy with opening of the dura and freeing of adhesions (adhesiolysis) was performed in five cases. In two patients cystic cavitations of spinal cord were observed, combined with atrophic changes. Two patients with cervical laminectomy showed moderate improvement. Three patients with circumscribed lower thoracic adhesions and partial or complete paraplegia did not benefit from surgery. In another patient, surgical freeing of massive adhesions at the cerebellopontine angle and local application of cortisone led to satisfactory improvement of symptoms which pre-operatively mimicked acoustic neurinoma (microsurgery performed by Prof. R. Ruberti, Nairobi).

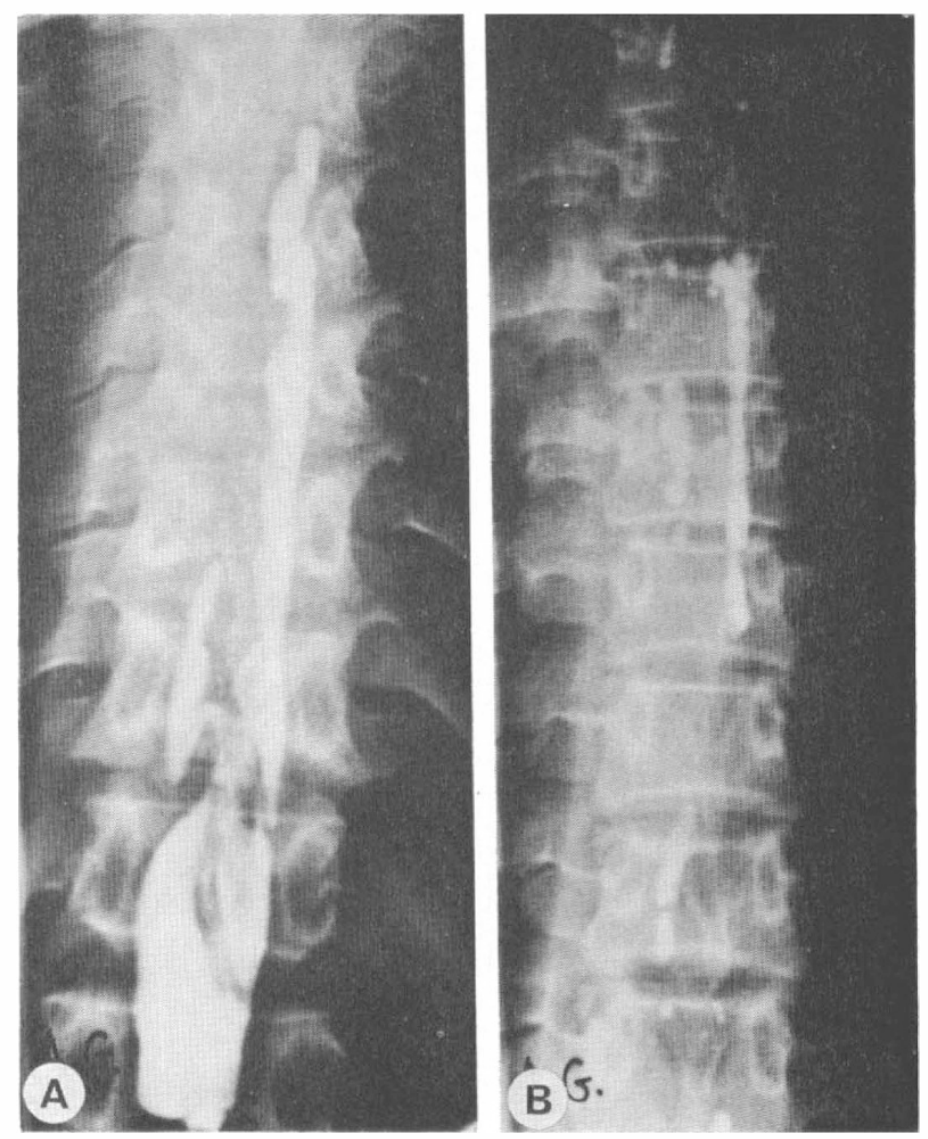

FIG. 2

A. At first almost complete blockage of contrast medium flow at LI-Ti2. B. The coughing manoeuvre led to 'break-through', and narrow, irregular passage of contrast medium, on the right side only, up to $\mathrm{C}_{5}$ level. 


\section{Discussion}

Adhesive spinal arachnoiditis unrelated to trauma has not been described previously in Ethiopia. Our investigation shows that the disorder is a common source of neurological complaints and disabilities. A similar syndrome has been reported from widely separated tropical regions, including India (Dastur \& Wadia, I969; Wadia \& Dastur, I969; Mani, I973), Singapore (Ransome \& Montiero, I947), Malaysia (Selby, I973) and Jamaica (Rodgers \& Cruickshank, I962; Cruickshank, I973).

Series of cases have been reported from other African countries, Kenya (Ojiambo, I966; Harries, I973), Nigeria (Ojikutu, I97I; Osuntokun, I973), Uganda (Shaper \& Shaper, I958; Murphy \& Hardikar, I968; Billinghurst, I970 and 1973), Rhodesia (Levy \& Axton, I973), Ghana (Haddock, 1973), Senegal (Collomb et al., I973) and South Africa (Cosnett, I973, I973a). Leigh (1976) presented ten cases of Tanzanians with paraplegia and complete myelographic obstruction of the middle or lower thoracic space in whom only arachnoiditis was surgically proved.

We wonder how many patients with 'obscure myelopathy' and 'other spinal cord syndromes' (Osuntokun, 1973), sensory ataxia-optic atrophy syndrome'

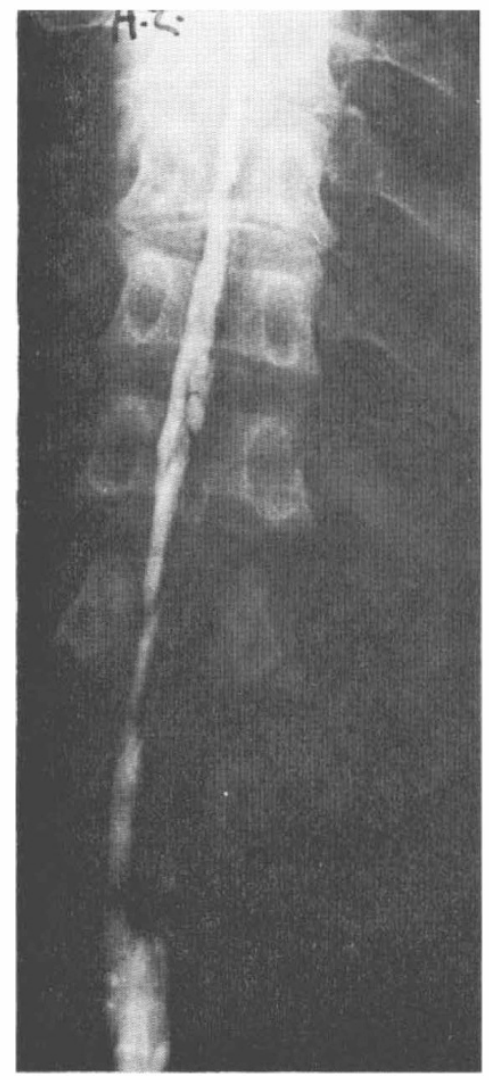

FIG. 3

An impressively slow and filiform passage of oil contrast throughout the entire T-C arachnoidal space. 
(Wadia, I973), or 'tropical spastic paraplegia', 'paraplegia: type unknown', 'spastic myelopathy' (all by Mani, 1973, Cosnett, I973 and others) were in fact suffering from chronic leptomeningitis, i.e. adhesive arachnoiditis. The similarities of almost all clinical criteria in our patients and those patients of Mani (1973) in South India with, e.g. 'tropical spastic paraplegia' are evident.

The question of 'negative myelography' is a difficult one, especially in cases with mild adhesions where so much depends on experience. Sometimes where advanced changes would be expected only slight spinal adhesions are found, not corresponding to the clinical picture. In such cases one should also examine the upper cervical region and the passage into the posterior fossa (cisterna magna cerebello-medullaris).

In the majority of the previous reports the presence of the dissociated sensory loss (syringomyelic sensory type), so characteristic of the patients in the present investigation has either not been mentioned or, the possible relationship between adhesive arachnoiditis and spinal cord cavitation (Nagpal et al., 1975) has been neglected. There is insufficient information in other African series to determine the nature of the sensory impairment. In all four cases of tuberculous meningitis of Ransome and Montiero (1947), 'sensory loss was most marked to pin-prick; hot and cold, postural sensibility, vibration sense and touch were little affected'. The clinical features in the Indian cases were described (Wadia \& Dastur, I969) in detail and it is clear that such a pattern was not present. Reporting on South Indian patients suffering from the so-called 'tropical spastic paraplegia', Mani

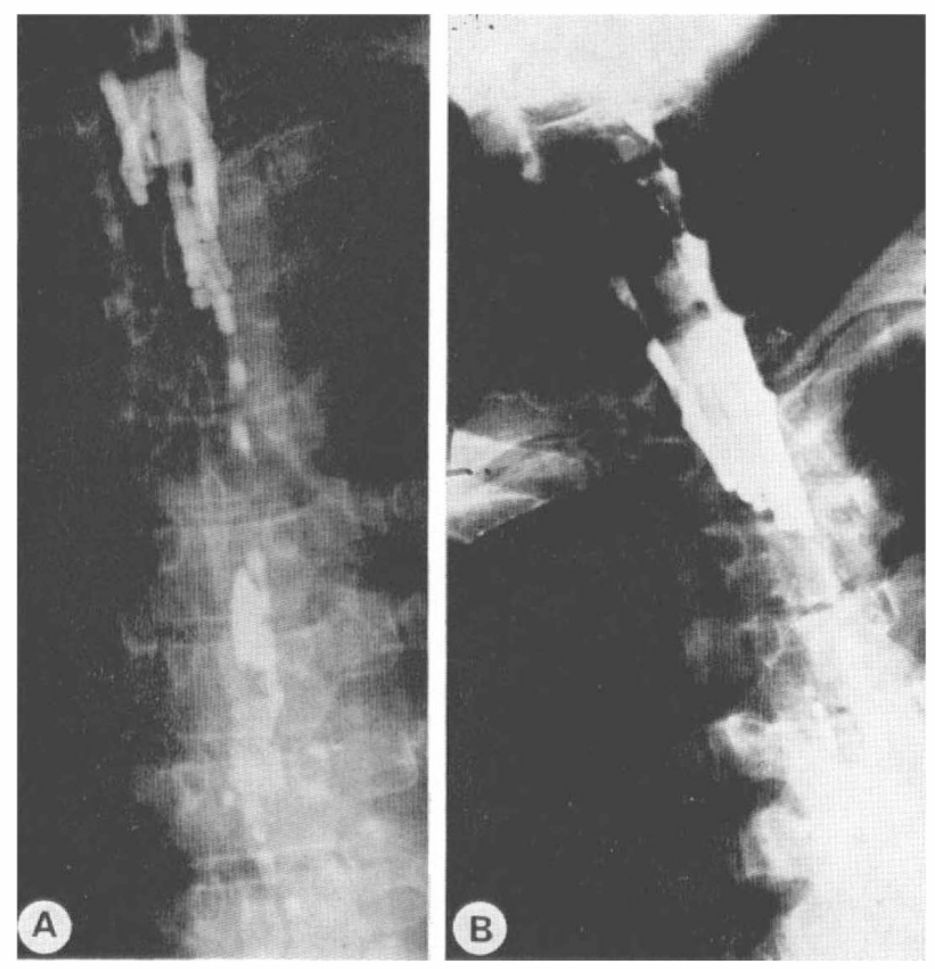

FIG. 4

Marked narrowing and irregularities particularly in thoracic (A), and less in the cervical section $(\mathrm{B})$. Contrast medium was passing poorly. 
(I973) describes a 'diminution of appreciation of touch, pain and temperature ... far from impressive'. Rodgers and Cruickshank (1962) found the following signs in their 20 Jamaican patients: 'The pyramidal tracts were invariably the most severely affected, but posterior column and, more frequently spinothalamic sensation were also involved' (features almost identical with those of our patients).

The pathogenetic mechanism of the sensory dissociation in our cases is uncertain. There are numerous earlier reports of an association between 'adhesive pachymeningitis' (arachnoiditis) and cavitation of the spinal cord (Charcot \& Joffroy, I869; Schwarz, I897; Holmes \& Kennedy, I908; Martin, I925; Lubin, I940; Nielsen, I953). In cases of cavitation with underlying adhesive arachnoiditis a circulatory impairment of the spinal cord was considered as a possible pathogenetic mechanism. A greater role than that of thickening of the vessel walls causing diminution of the blood supply (Tauber \& Langworthy, I935; Lubin, I940; McLaurin et al., I954), may be played by impaired venous drainage (venostasis) from the cord with resulting ischaemia (Stevenson, cited by Nelson, I943).

Appleby et al. (1969) postulated an association between hydromyelia and adhesive arachnoiditis around the outflow foramina of the 4th ventricle and generally at the foramen magnum to be caused by Gardner's (1965) hydrodynamic mechanism (pulsatile CSF pressure from the ventricular system into central canal -communicating syringomyelia).

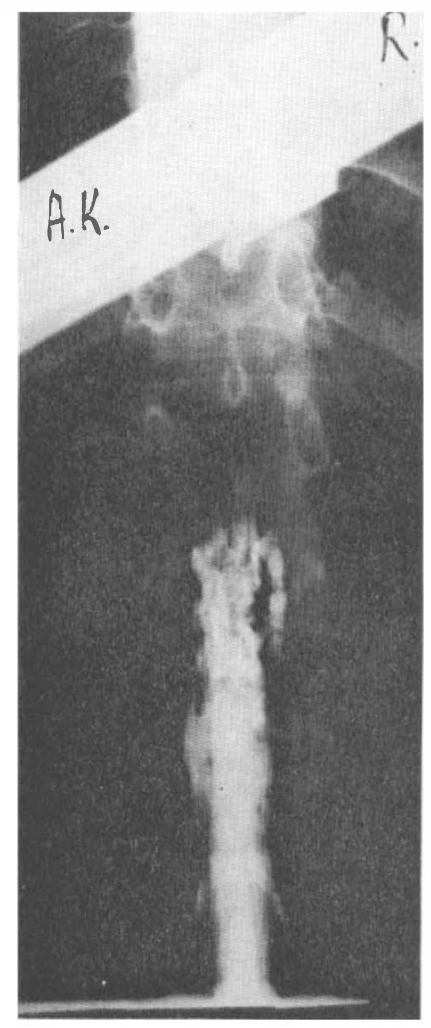

FIG. 5

Full blockage of oil contrast flow at the level LI-2 with typical 'candle-guttering'. 
We have been unable to determine whether cavitations of the spinal cord (distension of central canal more probable) were present in our patients since post-mortem was not permitted. Myelography at cervical space has rarely shown a significant enlargement of the cervical spinal cord as indirect evidence of hydromyelia. This, however, would not appear to be evidence enough against a hydrodynamic disorder (Foster \& Hudgson, I973) as it depends on the position of the body during myelography (Heinz et al., 1966). Williams (1970, 1970a, 1974, I976, I977, I977a, I978) and Barnett (1973, I976) have extensively dealt with the problem of syringomyelia caused by arachnoiditis. Williams has not been satisfied by a simplified hydrodynamic principle as a cause of syringomyelias. The blockage of the subarachnoid space at the foramen magnum, causing differences in 'venous' pressure between the head and the spine (I970a), 'is more likely to cause filling of the syrinx than funnelling of the "arterial" pulsations within the CSF pathways . . . incriminated by Gardner' (Williams, I978). The 'cranio-spinal pressure dissociation' of Williams originates 'from a valve-like action at the foramen magnum which causes a difference in pressure consequent upon the shifts of CSF caused by the imposition of energy from the venous system' (Williams, 1978).

The results of our study of 507 cases of spinal cord syndromes of the syringomyelic type revealed a close association with non-traumatic postinflammatory spinal and/or cisternal arachnoiditis. We agree with Barnett (I973) who postulated two pathogenetic aspects of syringomyelia due to arachnoiditis: (a) Adhesive cisternal arachnoiditis (foramen magnum level) alone is causing syringomyelic syndromes; (b) Spinal arachnoiditis, causing local adhesions at any level, can by itself present with clinical features resembling classical syringomyelia. In addition, partial or total vascular obstruction may cause painful radiculopathies and myelopathies, reaching complete transverse spinal cord lesion.

\section{Aetiology}

While the aetiology of the spinal arachnoiditis syndrome in Ethiopia must remain uncertain because of the absence of post-mortem examinations, there is indirect evidence to suggest that infections are involved in a significant number of patients. Arachnoiditis followed classical bacterial meningitis in seven patients. In the remainder, two specific infections, tuberculosis and syphilis, warrant particular attention.

There is good evidence that arachnoiditis in Asia is commonly a sequel of tuberculosis (India: Wadia \& Dastur, I969; Udani et al., I97I; Thailand: Vejiajiva, 1974). Tuberculosis is widespread in Ethiopia (Susteric, 1976), and the Mantoux test was positive in 92 per cent of our patients. A causative connection between tuberculous infection and arachnoiditis is probable in some of our cases and the syndrome followed tuberculous meningitis in two patients. In another, wasting of the hands and syringomyelic pattern of sensory loss developed 18 months after the patient presented with thoracic spinal tuberculous caries. In the majority of our patients, however, there was no evidence of active tuberculous infection.

It is of particular interest that Emond et al. (I973) have shown that tuberculosis can produce a transient aseptic meningitis and, in one of his five patients with discrete meningeal symptoms, the CSF contained normal protein and glucose levels without pleocytosis. Nevertheless, guinea-pig inoculation revealed tuberculosis. This patient recovered without therapy. The transient febrile illness which preceded the onset of neurological symptoms in many of our patients would be compatible with an episode of tuberculous meningeal infection of this 
type. The CSF for tuberculous-culture or guinea-pig inoculation should have been taken immediately at the onset of fever.

Earlier authorities considered syphilis to be a causative agent of adhesive arachnoiditis in many cases. Horsley (1909) suggested that not only syphilis but also gonorrhoea were responsible for his 'Chronic Spinal Meningitis' patients. In fact, all the authors from Asia and Africa dealing with the problem do accept syphilis as a cause of the meningovascular changes, luetic meningitis and arachnoiditis. Doing so they refer to a rather high incidence of VDRL positive serum (mostly negative in CSF), and emphasise that the 'diagnosis (of neurosyphilis) must frequently be based on positive blood serology alone' (Cosnett, I973).

However, the role of syphilis seems to us even less clear and certain than the role of tuberculosis. Apart from the fact that there is no difference in the clinical findings in VDRL positive patients and those with VDRL negative reactions and a convincingly negative history for syphilis, the overall incidence of a positive VDRL test in the blood was I5 per cent (Table III), as compared with the 8 to II per cent of the general population in Addis Ababa and surrounding areas (Friedmann, 1976). The test was negative in the CSF in all examined patients, even in those ten serum positive patients who had a lumbar puncture prior to any treatment with antibiotics. It is probable, however, that the true incidence of syphilis was higher, since 8 per cent of the VDRL negative patients had Argyll Robertson pupils and approximately 50 per cent of the whole series, retrospective and prospective, had been treated for gonorrhoea at least once, commonly without prior VDRL test. It is interesting that one of our three European patients, a 6o-year-old male, acquired syphilis 3 years before he insidiously developed the clinical and radiological patterns or arachnoiditis which we have described in the Ethiopians. At the time he acquired syphilis he felt a general malaise. VDRL repeatedly confirmed the diagnosis. Ten days after luetic contagion Penicillin and another antibiotic (probably Tetracycline) were introduced. After 3 weeks of treatment he felt well again.

We conclude that it is likely that a percentage of cases of arachnoiditis in Ethiopia are due to syphilis.

What of the future?

It is unlikely that progress in understanding the aetiology of the disease in Ethiopia will be made before post-mortem becomes acceptable. The evidence that syphilis and particularly tuberculosis are a significant cause for this common disorder is nevertheless good enough to urge that patients acquiring syphilis or tuberculosis should receive vigorous treatment by antibiotics and chemotherapeutics respectively at the earliest stage of infection. Assuming that syphilis is a cause of arachnoiditis the immediate treatment is decisive in preventing the later sequelae. After contagion with treponema pallidum treatment must be started within the next few days. In our experience, therapeutic efforts that are only

\section{TABLE III}

Evidence of syphilis in the prospective series

\begin{tabular}{|c|c|c|c|}
\hline & Total & Male & Female \\
\hline All patients & $353 / 100 \%$ & $2 \mathrm{I} 8 / 6 \mathrm{I} \cdot 8 \%$ & $135 / 38 \cdot 2 \%$ \\
\hline VDRL positive & $53 / 15 \%$ & $42 / 19 \cdot 2 \%$ & $\mathrm{II} / 8 . \mathrm{I} \%$ \\
\hline $\begin{array}{l}\text { Argyll Robertson pupils on } \\
\text { VDRL negat. patients }\end{array}$ & $30 / 8 \cdot 4 \%$ & $20 / 9.1 \%$ & Io/ $7 \cdot 4 \%$ \\
\hline
\end{tabular}


begun 7 to Io days post-contagion are unlikely to prevent the patients from developing vascular and/or arachnoidal luetic lesions.

Differential diagnosis of tuberculous or syphilitic leptomeningitis (arachnoiditis) should be considered in patients presenting with diminution of vision, diplopia, facial palsy, vertigo and decreased hearing and other cranial nerve lesions. On the other hand, in patients with a spinal cord lesion at any level a myelogram should be performed to exclude a surgically curable compression such as tumours, disc prolapses and other conditions.

Although there have been some reports of satisfactory results after surgical treatment of arachnoiditis (Teng \& Papatheodorou, I967; Jorgensen et al., I975; Tedeschi \& Benini, I976), our own experience and that of a number of other authors have been disappointing (Lombardi, et al., 1962; Barnett, Foster \& Hudgson, 1973; Leigh, I976), except for secondary hydrocephalus which can be treated by shunting (Appleby et al., 1969). Posterior fossa surgery has been critically re-evaluated (Williams, I978) and will be limited for a very carefully selected group of patients.

Acknowledgements. The authors wish to thank Prof. Dr G. Neff, Swiss surgeon in Addis Ababa, and Prof. Dr R. Ruberti, Nairobi, for performing surgery. Prof. Dr J. Landells, British pathologist in Addis Ababa, for invaluable comments, and Prof. I. W. McDonald, London, U.K., for his helpful criticism by reviewing the paper. All the staff of the Radiological Department of Black Lion Hospital, Addis Ababa, for their enthusiastic cooperation.

\section{SUMMARY}

Spinal cord syndromes with a mainly syringomyelic pattern of sensory disorders, radiculopathies, mixed paresis of varying degrees (without any history of trauma), have been found in 507 out of 1305 new patients referred to our Clinic from January I976 till 31 October 1977. In I05 randomised and unselected cases with these syndromes, myelographies have disclosed findings compatible with an adhesive spinal and/or cisternal arachnoiditis. A prospective study of the syndromes for evidence of infectious aetiology has been performed, in which tuberculosis, syphilis and other infections appear to be causative agents. A randomised therapeutic trial on a limited number of cases has been evaluated, as well as the results of specific therapy in a larger number of cases. Results of treatment have not been satisfactory. Operations were performed on only five patients and in no case was an autopsy obtained. Spinal cord syndromes due to non-traumatic adhesive arachnoiditis are discussed. The possible pathogenetic mechanisms of the predominantly syringomyelic sensory deficits in those syndromes are briefly mentioned.

\section{RÉSUMÉ}

Les syndromes de la moelle épinière, avec un ensemble principalement syringomyélique de désordres sensoriels, de radiculopathies, de paralysies conjointes de divers degrés, sans aucune origine traumatique, ont été observés dans 507 cas des 1305 patients confiés à notre Clinique, etre le mois de janvier 1976 et le 3 I octobre 1977.

Dans I05 cas pris au hasard et non-sélectionnés présentant ces syndromes, les myélographies ont révélé des résultats compatibles avec une arachnoïdite spinale ou citernale. On a fait une étude éventuelle des syndromes pour déceler l'évidence d'une étiologie infectieuse et il semble, en effet, que la tuberculose, la syphilis et d'autres maladies infectieuses soient à l'origine de ces cas. Un essai thérapeutique fait au hasard sur un nombre limité de cas aussi bien que le résultat d'une thérapeutique spécifique sur un plus grand nombre de malades n'ont pas donné de résultats satisfaisants. Seuls cinq patients ont subi une 
opération. Aucun cas ne nous a donné un résultat d'autopsie. Les syndromes postinflammatories de la moelle épinière et la pathogénèse de la syringomyélie qui y est associée à la suite d'une arachnoïdite adhésive sont brièvement discutés.

\section{ZUSAMMENFASSUNG}

Rüchenmarkssyndrome mit überwiegend syringomyelischen Sensibilitätsausfällen, Radikulopathien, gemischten Paresen wechselnden Grades, ohne Unfallanamnese, wurden bei 507 von I305 Patienten gefunden, welche von Januar 1976-31. Oktober 1977 an unsere Klinik überwiesen wurden. Die Myelographie deckte bei I05 randomisierten und unselektierten Fällen mit diesen Syndromen Befunde auf, die mit adhesiver spinaler und/oder cisternaler Arachnoiditis vereinbar sind. Es wurde eine prospektive Studie zum Nachweis einer infektiösen Aetiologie durchgeführt. Aus dieser geht hervor, daß Tuberkulose, Syphilis und andere Infektionen als ursächliche Faktoren erscheinen. Bei einer begrenzten Anzahl von Patienten wurde ein therapeutischer Versuch und bei einer größeren Gruppe die Resultate der spezifischen Therapie ausgewertet. Die Resultate der Therapie waren unbefriedigend. Nur fünf Patienten wurden operiert. Es wurde keine Autopsie durchgeführt. Rückenmarkssyndrome verursacht durch nicht-traumatische adhesive Arachnoiditis werden diskutiert. Die möglichen pathogenetischen Mechanismen der überwiegend syringomyelischen Sensibilitätsausfälle bei diesen Syndromen werden erwähnt.

\section{REFERENCES}

Appleby, A., Bradley, W. G., Foster, J. B., Hankinson, J. \& Hudgson, P. (i969). Syringomyelia due to chronic arachnoiditis at the foramen magnum. F. neurol. Sci., $8,45 I-464$.

ARseni, C. \& SAMitiCA, D. C. (I960). Intraspinal tuberculous granuloma. Brain, 83, 285-292.

BARNETT, H. J. M. (I973). Syringomyelia associated with spinal arachoniditis. In H. J. M. BARnetT, J. B. Foster \& P. Hudgson (eds.), Syringomyelia. W. B. Saunders Co., Ltd., London, Philadelphia, Toronto, pp. 224-24I.

Bawa, Y. S. \& WAHI, P. L. (I96I). Spinal tuberculous meningitis. F. Indian med. Ass., 37, 449 .

BILlinghURST, J. R. (1970). The pattern of adult neurological admissions to Mulago Hospital, Kampala. E. Afr. med. F., 47, 653-663.

Billinghurst, J. R. (I973). Neurological disorders in Uganda. In J. D. SPILlane (ed.): Tropical Neurology. Oxford University Press, London, pp. 19I-206.

Brouwer, B. (I93I). Ueber Arachonoiditis adhesiva circumscripta. Deutsche Ztschr. $f$. Nervenh., 38, I I 7-I I9.

Charcot, J. M. \& Joffroy, A. (I869). Deux cas d'atrophie musculaire progressive avec lésions de la substance grise et des faisceaux anterolateraux de la moelle épinière. Archives de Physiologie, 2, 354.

Collomb, H., Dumas, M. \& Girard, P. L. (1973). Neurological disorders in Senegal. In Spillane (1973, pp. I33-I42).

Cosnett, J. E. (1973). Neurological Diseases. In G. D. Campbell, Y. K. Seedat \& G. Daynes (eds.), Clinical Medicine in Africans in Southern Africa. Churchill Livingstone, Edinburgh and London, pp. 346-374.

Cosnett, J. E. (1973a). Neurological disease in Natal. In Spillane (1973, pp. 259-272).

Cruickshank, E. K. (I973). Neurological disorders in Jamaica. In Spillane (1973, pp. $42 \mathrm{I}-434)$.

DASTUR, D. K. \& WAdiA, N. H. (1969). Spinal meningitides with radiculo-myelopathy, Part 2: Pathology and pathogenesis. F. neurol. Sci., 8, 26I-297.

Elkington, J. St. C. (I936). Meningitis serosa circumscripta spinalis (spinal arachnoiditis). Brain, 59, $18 \mathrm{I}-203$.

Emond, R. T. \& KENDRICK, G. D. (I973). Tuberculosis as a cause of transient aseptic meningitis. Lancet, $\mathbf{I}, 234-236$.

Foster, J. B. \& Hudgson, P. (I973). The pathology of communicating syringomyelia. In Ibid. BARNETT, pp. 95-IO3.

FreIlich, D. \& SWASH, M. (I979). Diagnosis and management of tuberculous paraplegia with special reference to tuberculous radiculomyelitis. F. Neurol. Neurosurg. Psychiat., 42, I 2-I 8 . 
FrIEDMANN, P. (1976). Observation on the prevalence of syphilis in Ethiopia. Report on the occasion of the XIIth annual medical conference, Addis Ababa, May 28, 1976.

GARDNER, W. J. (1965). Hydrodynamic mechanism of syringomyelia; its relationship to myelocele. F. Neurol. Neurosurg. Psychiat., 28, 247-259.

HADDOCK, D. R. W. (1973). Neurological disorders in Ghana. In Spillane (1973, pp. I43-I60).

HarRIES, J. R. (1973). Neurological disorders in Kenya. In Spillane (1973, pp. 207222).

Heinz, E. R., Schlesinger, E. B. \& Potts, D. G. (1966). Radiologic signs of hydromyelia. Radiology, 86, 3I I-3I8.

Holmes, G. \& KenNEDY, R. F. (1908). Two anomalous cases of syringomyelia. Proceedings of the Royal Society of Medicine, 2: I.

HoRsLeY, Sir V. (1909). A clinical lecture on chronic spinal meningitis. Its differential diagnosis and surgical treatment. Brit. Med. fournal, i, 5 I3.

JENkINS, R. B. (I963). Intradural spinal tuberculoma with genito-urinary symptoms. Arch. Neurol. (Chic.), 8, 539-543.

Joffroy, A. (1873). De la pachymeningite cervicale hypertrophique. Thesis, Paris.

JoRgensen, J., HANSEN, P. H. \& Ovesen, N. (1975). A clinical and radiological study of chronic lower spinal arachnoiditis. Neuroradiology, 9, I39-I 44.

LEIGH, P. (I976). A survey of spinal cord and cauda equina syndromes in Dar-es-Salaam. Report on the occasion of the Third Annual Conference of Neurological Society of Kenya, Nairobi, April, 1976.

Levy, L. F. \& Axton, J. (1973). Neurosurgery in Rhodesia. In Spillane (1973, pp. 223-236).

Lombardi, G., Passerini, A. \& Migliavacca, F. (1962). Spinal arachnoiditis. $B r . \mathcal{F}$. Radiol., 35, 314-320.

LubIN, A. J. (I940). Adhesive spinal arachnoiditis as a cause of intramedullary cavitation. Arch. Neurol. Psychiat. (Chic.), 44, 409-420.

Mani, K. S. (1973). Neurological disease in South India. In Spillane (1973, pp. 78-87).

MARTIN, J. P. (I925). Amyotrophic meningo-myelitis (spinal progressive muscular atrophy of syphilitic origin). Brain, 48, I53-182.

Mclaurin, R. L., Bailey, O. T., Schurr, P. H. \& Ingraham, F. D. (I954). Myelomalacia and multiple cavitations of spinal cord secondary to adhesive arachnoiditis. An experimental study. Archives of Pathology, 57, I38-146.

Murphy, N. B. \& HaRdikaR, S. M. (I968). Non-traumatic paraplegia in Uganda. A review of 23 cases with spinal canal obstruction. E. Afr. med. F., 45, I77-189.

Nagpal, R. D., Gokhale, S. D. \& PARIKH, V. R. (I975). Ossification of spinal arachnoid with unrelated syringomyelia. $\mathcal{F}$. Neurosurg., 42, 222-225.

NeLsoN, J. (I943). Intramedullary cavitation resulting from adhesive spinal arachnoiditis. Arch. of Neurol. Psychiat., 50, I-7.

Nielsen, J. M. (I953). Progressive course of arachnoiditis simulating syringomyelia. Tr. Am. Neurol. A., 77, I74-178.

Ojiambo, H. P. (1966). Neurological disease at Kenyatta National Hospital, Nairobi. A retrospective study of 75 cases. E. Afr. med. F., 43, 366-376.

OJikutu, N. A. (197I). Paraplegia. Nigerian Med. fournal, I, 42-43.

Osuntokun, B. O. (1973). Neurological disorders in Nigeria. In Spillane (1973, pp. I6I-I90).

Parsons, M. \& Pallis, C. (1965). Intradural spinal tuberculomas. Neurology (Minneap.), 15, IOI 8-1022.

RANsome, G. A. \& Montiero, E. S. (1947). A rare form of tuberculous meningitis. Brit. med. F., I, 413-4I4.

Rodgers, P. E. B. \& CRUICKSHANK, E. K. (1962). Spinal arachnoiditis. W. Indian med. F., II, I64-I70.

ScHwarTZ, E. (I897). Praeparate von einem Falle syphilitischer myelomeningitis mit Höhlenbildung im Rüchenmark und besonderen degenerativen Veränderungen der Neuroglia. Wiener Klinische Wchschr., 10, I77.

SELbY, R. (1973). Neurological disorders in Malaysia. In Spillane (1973, pp. 299-320).

SHAPER, A. G. \& SHAPER, L. (1958). Analysis of medical admissions to Mulago Hospital, 1957. E. Afr. med. F., 35, 647-669.

Shaw, M. D. M., Russell, J. A. \& Grossart, K. W. (1978). The changing pattern of spinal arachnoiditis. F. Neurol. Neurosurg. Psychiat., 4I, 97-107.

I $9 / 2-\mathrm{C}$ 
Spillane, J. D. (1973). Tropical Neurology. Oxford University Press, London.

Susteric, J. (1976). Tuberculosis control in Ethiopia. Report on the occasion of the XIIth Annual Medical Conference of the Ethiopian Medical Association, May 29, 1976.

Stevenson, L. (1943). Cited by Nelson (q.v.).

TANDON, P. N. \& Pathak, S. N. (I973). Tuberculosis of the central nervous system. In Ibid. BillinghuRst, pp. 37-62.

TAUBer, E. S. \& LANGWORTHY, O. R. (1935). A study of syringomyelia and the formation of cavities in the spinal cord. F. Nerv. E Ment. Dis., 81, 245-264.

Tedeschi, N. \& BeninI, A. (I976). Leptomeningitis chronica fibro-plastica der cauda equina als Ursache ischias-ähnlicher Beschwerden. Neurochirurgia, 19, 84-90.

TekLu, BAYu. (1975). Mantoux tests. Observer variability in reading Mantoux tests. Eth. Med. Fournal, 13, I47-I53.

Teng, P. \& Papatheodorou, CH. (1967). Myelographic findings in adhesive spinal arachnoiditis (with a brief surgical note). Br. F. Radiol., 40, $20 \mathrm{I}-208$.

UdANI, P. M., PAREKh, U. C. \& DASTUR, D. K. (I97I). Neurological and related syndromes in CNS Tuberculosis. F. neurol. Sci., 14, 34I-353.

VejJajiva, A. (1974). Neuro-Tuberculosis: an unsolved problem. F. Med. Assoc. Thai., 57, 89-92.

WADIA, N. H. \& DASTUR, D. K. (1969). Spinal meningitides with radiculo-myelopathy. Part I. Clinical and radiological features. F. neurol. Sci., 8, 239-260.

WADIA, N. H. (1973). Radiculomyelopathy associated with spinal meningitides (arachnoiditis) with special reference to the spinal tuberculous variety. In Spillane (1973, pp. 63-72).

WILlIAMS, B. (1970). The distending force in the production of communicating syringomyelia. Lancet, 2, 4I-42.

Williams, B. (I970a). Current concepts of syringomyelia. British fournal of Hospital Medicine, 4, 33I-342.

Williams, B. (I974). A demonstration analogue for ventricular and intraspinal dynamics (DAvid). f. neurol. Sci., 23, 445-46I.

Williams, B. (1976). Cerebrospinal fluid pressure changes in response to coughing. Brain, 99, 33 I-346.

Williams, B. (I977). Difficult labour as a cause of communicating syringomyelia. Lancet, 2, 50-53.

Williams, B. (1977a). On the pathogenesis of the Chiari malformation. Zeitschrift für Kinderchirurgie und Grenzgebiete, 22, 533-553.

Williams, B. (I978). A critical appraisal of posterior fossa surgery for communicating syringomyelia. Brain, 101, 223-250. 